\title{
The relations between internet using as a learning media and the interest in learning of guidance and counseling study program students
}

\author{
Nur Wisma $^{\left.1^{*}\right)}$, Faradillah Rahayu Metrin ${ }^{1}$ \\ ${ }^{1}$ Universitas Sriwijaya, Palembang, Indonesia
}

\section{Article Info}

\section{Article history:}

Received Des $12^{\text {th }}, 2021$

Revised Jan $9^{\text {th }}, 2022$

Accepted Jan $27^{\text {th }}, 2022$

\section{Keyword:}

Internet use

Learning media

Interest in learning

\begin{abstract}
This quantitative descriptive research is an correlational, aiming to determine the relationship between the use of the internet as a learning medium and the learning interest of the 2018 students of the Guidance and Counseling study program at Sriwijaya University. The population in this study were 70 students and a sample of 64 students using proportional random sampling technique. The data collection instrument used a questionnaire using a Likert scale. The data analysis used was the product moment correlation. The results of the analysis obtained a correlation coefficient of 0.574 which indicates that the use of the internet as a learning medium with student interest in learning has a relationship with a rather low level of relationship at a significance level of 0.05 . So it can be concluded that there is a relationship between the use of the internet as a learning medium and the interest in learning of students from the 2018 batch of the guidance and counseling study program FKIP Sriwijaya University.
\end{abstract}

(C) 2022 The Authors. Published by IICET.

This is an open access article under the CC BY-NC-SA license

(https://creativecommons.org/licenses/by-nc-sa/4.0

\section{Corresponding Author:}

Wisma, N.,

Universitas Sriwijaya, Palembang, Indonesia

Email: nurwisma@fkip.unsri.ac.id

\section{Pendahuluan}

Pendidikan secara khusus dapat diartikan sebagai sebuah wadah beraktivitas dalam lingkup sekolah yang kegiatannya adalah melakukan kegiatan belajar-mengajar baik nonformal maupun formal yang dilakukan secara teratur serta terus menerus dan terencana (Kadir, 2012). Secara umum pendidikan telah diberikan kepada seorang individu dari masa kanakkanak hingga ke jenjang yang lebih tinggi yaitu pada jenjang perguruan tinggi. Perguruan tinggi atau Universitas merupakan sebuah hal sangat penting yang keberadaannya pun diakui oleh berbagai masyarakat di suatu negara. Universitas atau perguruan tinggi merupakan pusat pendidikan tinggi yang dituntut untuk dapat menciptakan lulusan yang memiliki pribadi berkualitas serta dapat berguna dan mengabdi kepada Negara maupun masyarakat. Gialamas (2013), melakukan penelitian yang berkaitan mengenai dampak pada penggunaan internet terhadap pembelajaran dan pekerjaan di masa depan. Penelitian ini dilakukan dengan melibatkan 448 mahasiswa program studi PAUD di Universitas Nasional Athena dan menunjukkan hasil bahwasannya sebesar 80\% mahasiswa menyatakan setuju bahwa internet dapat membantu dan mendorong sebuah proses belajar menjadi lebih menarik, sedangkan sisanya yaitu $65 \%$ mahasiswa menyatakan setuju bahwa dengan adanya penggunaan internet dapat menunjang dalam meningkatkan kualitas sebuah pembelajaran.

Variabel yang ditetapkan pada penelitian yaitu Internet Usage sebagai indikator yang diambil untuk dapat melakukan pengukuran dari penggunaan dan minat belajar dengan menggunakan internet. Internet 
diharapkan dapat meningkatkan minat belajar pada mahasiswa saat melakukan kegiatan pembelajaran, hadirnya internet juga diharapkan dapat membantu dan menunjang adanya peningkatan dalam pengembangan ilmu pengetahuan terhadap teknologi dan informasi yang setiap tahunnya terus berkembang di seluruh dunia. Internet dapat berguna dan berfungsi sebagai sebuah alat yang dapat membantu proses seorang individu dalam mencari informasi serta pelajaran tambahan dan dapat menciptakan minat/rasa ketertarikan. Simatupang (2017), pada penelitiannya yang berkaitan dengan hubungan penggunaan media internet dengan minat belajar siswa kelas XI di SMA Muhammadiyah 2 Yogyakarta menunjukkan hasil bahwasannya terdapat keterkaitan dan terdapat hubungan positif antara penggunaan media berbasis internet dengan minat belajar siswa. Hal ini dapat dilihat dan diukur dengan adanya hasil dari nilai koefisien yaitu sebesar 0,0052 yang mana berada pada tingkat sedang sehingga dapat dikatakan bahwasannya terdapat hubungan yang signifikan antara penggunaan media berbasis internet terhadap minat siswa. Berdasarkan hasil dari penelitian yang dilakukannya maka dapat ditarik kesimpulan bahwasannya semakin tinggi penggunaan internet maka semakin tinggi pula minat belajar siswa tersebut

Penggunaan internet serta dalam sebuah ruang lingkup perguruan tinggi masih banyak dijumpai penyalahgunaannya. Internet tidak hanya dapat digunakan sebagai perantara dari alat komunikasi secara online sehari-hari saja namun internet juga dapat dimanfaatkan sebagai penunjang dalam sebuah proses akademik. Namun pada kenyataannya dalam sebuah proses pembelajaran diperguruan tinggi, internet lebih banyak dimanfaatkan untuk kegiatan non-akademik seperti bermain media sosial, bermain game online dan mengakses situs yang tidak ada kaitannya dengan proses akademik. Masih banyak mahasiswa/i yang masih belum memahami tentang bagaimana memanfaatkan sebuah informasi dan materi yang didapatkan serta bersumber dari internet dengan benar dan baik sehingga dapat menunjang proses akademiknya juga, selain itu adanya kemudahan akses melalui internet dapat menunjang sebuah pelajaran untuk dapat lebih mudah dipahami dan dimengerti. Oleh karena itu, pembuktian dari adanya rumusan masalah mengenai apakah ada atau tidaknnya sebuah hubungan yang positif atau signifikan antara penggunaan internet sebagai media pembelajaran dengan minat belajar yang secara spesifik peneliti lakukan pengujian terhadap mahasiswa Bimbingan dan Konseling angkatan 2018 di Fakultas Keguruan dan Ilmu Pendidikan Universitas Sriwijaya.

\section{Metode}

Jenis dari penelitian merupakan penelitian kuantitatif dengan metode penelitian korelasional. Penelitian kuantitatif merupakan sebuah penelitian yang dilakukan dengan cara mengumpulkan informasi mengenai data-data yang dikumpulkan melalui sampel yang telah ditentukan yang selanjutnya akan digunakan sebagai data dalam mencari sebuah jawaban dari rumusan masalah. Sedangkan penelitian korelasional merupakan sebuah penelitian yang dilakukan guna untuk mencari sebuah korelasi atau hubungan dari atau antar variabel satu dengan variabel lainnya yang telah ditentukan (Winarni, 2011).

Populasi pada penelitian ini adalah berjumlah 70 orang mahasiswa Bimbingan dan Konseling Angkatan 2018 yang terdiri dari 2 kelas yaitu kelas Indralaya dan kelas Palembang. Sampel dari penelitian ini adalah 64 orang mahasiswa yang ditentukan menggunakan metode Simple Random Sampling dan menggunakan teknik analisis data probability sampling dengan pengambilan sampel yang dilakukan menggunakan rumus slovin.

Pengumpulan data pada penelitian ini dilakukan dengan menggunakan instrumen penelitian yang digunakan untuk mengukur nilai variabel yang diteliti yaitu skala penggunaan media internet sebagai media pembelajaran dan skala minat belaar yang menggunakan skala pengukuran skala Likert dengan pilihan jawaban SS (Sangat Setuju, ST (Setuju), RG (Ragu-ragu), TS (Tidak Setuju), STS (Sangat Tidak Setuju). Adapun blueprint dari skala Penggunaan Internet Sebagai media pembelajaran dan skala Minat Belajar adalah sebagai berikut:

Tabel 1. Blueprint Skala Penggunaan Internet Sebagai Media pembelajaran

\begin{tabular}{llc}
\hline Variabel & Indikator & Jumlah item \\
\hline Penggunaan & Intensitas Penggunaan internet & 5 \\
internet sebagai & & \\
media & & \\
pembelajaran & Pemanfaatan Penggunaan Internet & 9 \\
& Penggunaan layanan internet & 7 \\
& $\quad$ Jumlah & 21 \\
\hline
\end{tabular}


Tabel 2. Blueprint Skala Minat Belajar

\begin{tabular}{|c|c|}
\hline Indikator & Jumlah item \\
\hline Perasaan senang & 3 \\
\hline Ketertarikan untuk belajar & 5 \\
\hline Menunjukkan perhatian saat belajar & 3 \\
\hline Keterlibatan dalam belajar & 3 \\
\hline Jumlah & 14 \\
\hline
\end{tabular}

Berdasarkan pada tabel 1 dan 2 diatas menunjukkan skala penggunaan internet sebagai media pembelajaran dan skala minat belajar disusun berdasarkan kajian teori dengan reabilitas sebesar 0,854 pada skala penggunaan internet sebagai media pembelajaran dan 0,802 pada skala minat belajar. Selanjutnya pengumpulan data dari penelitian dilakukan menggunakan bantuan google form dan melakukan analisis data menggunakan rumus korelasi Product moment melalui aplikasi SPSS versi 26, dengan hipotesis penelitian adalah terdapat Hubungan Penggunaan Internet Sebagai Media Pembelajaran Dengan Minat Belajar Mahasiswa Prodi Bimbingan Dan Konseling.

\section{HASIL DAN PEMBAHASAN}

\section{Analisis Deskriptif}

Hasil yang telah diperoleh melalui penelitian ini dapat dilihat pada gambar berikut ini yang menunjukkan data terkait gambaran tingkat dari Penggunaan internet sebagai media pembelajaran dan minat belajar yang dimiliki oleh mahasiswa program studi Bimbingan dan Konseling di Universitas Sriwijaya.

1. Penggunaan internet sebagai media pembelajaran

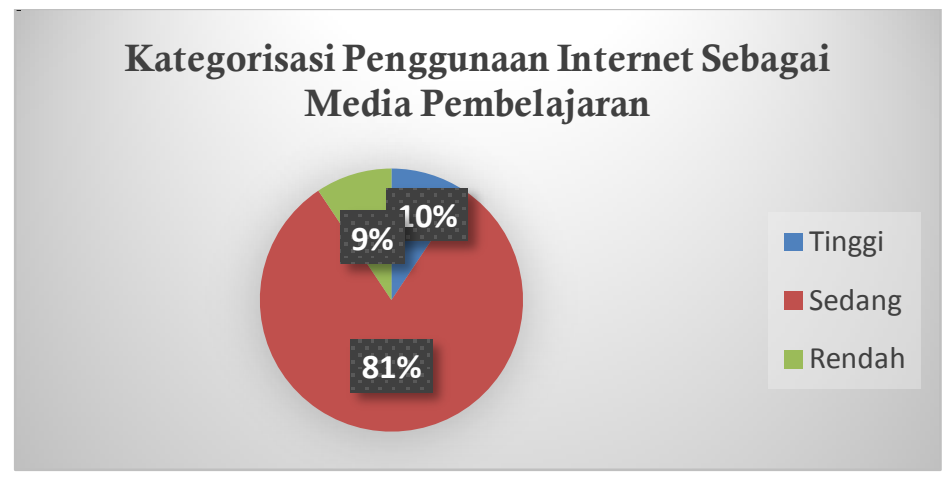

Gambar 1. Kategorisasi Penggunaan Internet Sebagai Media Pembelajaran

Berdasarkan gambar diatas, dapat disimpulkan bahwasannya tingkat penggunaan internet sebagai media pembelajaran pada mahasiswa Bimbingan dan Konseling Angkatan 2018 rata-rata berada di tingkat sedang. Pada kategori rendah sebesar 9\% yaitu sebanyak 6 mahasiswa dan pada kategori tinggi sebesar $10 \%$ yaitu sebanyak 6 mahasiwa. Dan pada kategori sedang sebesar $81 \%$ yaitu sebanyak 52 mahasiswa.

2. Penggunaan internet sebagai media pembelajaran

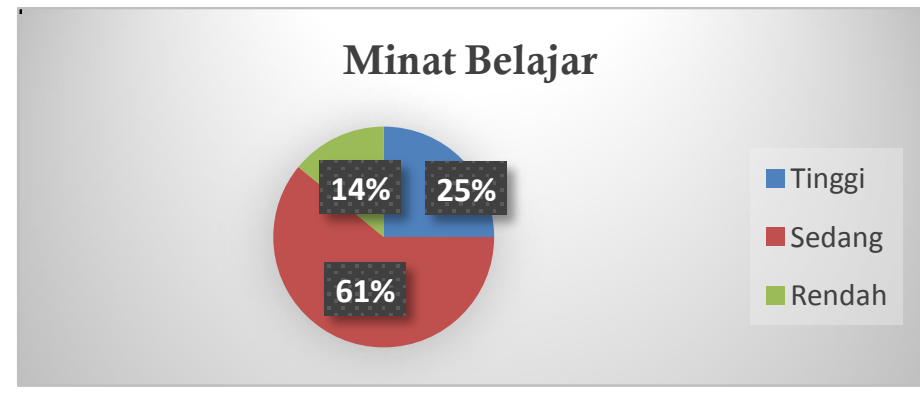

Gambar 2. Kategorisasi Minat Belajar

Berdasarkan dari gambar diatas, dapat disimpulkan bahwasannya tingkat minat belajar pada mahasiswa Bimbingan dan Konseling Angkatan 2018 rata-rata ada pada tingkat sedang. Sedangkan untuk 
kategori rendah sebesar 14\% yaitu sebanyak 9 mahasiswa dan pada kategori tinggi sebesar 25\% yaitu sebanyak 16 mahasiwa dan pada kategori sedang sebesar $61 \%$ yaitu sebanyak 39 mahasiswa.

\section{Analisis Korelasional}

\section{Uji Normalitas}

Pada sebuah penelitian, uji normalitas perlu untuk dilakukan untuk mengetahui bagaimana sebaran distribusi dari variabel bebas dan variabel terikat berdistribusi normal atau tidak. Metode yang dilakukan pada penelitian ini untuk menguji distribusi normalitas variabel adalah menggunakan kolmogrovSmirnov test yang dilakukan dengan bantuan aplikasi oleh data SPSS 26. Hasil dari uji normalitas tersebut dapat dilihat pada tabel berikut ini:

Tabel 3. One-Sample Kolmogorov-Smirnov Test

\begin{tabular}{lcc}
\hline & & Unstandariz Ed Residual \\
\hline $\mathrm{N}$ & & 64 \\
Normal Parameters & Mean & 0000000 \\
& Std. Deviation & 4.56612450 \\
Most Extreme Differences & Absoulute & .069 \\
& Positif & .069 \\
& Negative & -.055 \\
Test Statistic & & .069 \\
Asymp.Sig. (2-tailed) & & $.200^{\text {c.d }}$ \\
\hline
\end{tabular}

Hasil dari uji normalitas diatas menunjukkan bahwasannya hasil dari Asymp.sig (2-tailed) adalah sebesar 0.200 yang mana lebih besar dari 0,050 yang artinya data penelitian yang telah diperoleh memiliki distribusi normal dan dapat dilakukan uji analisis data selanjutnya agar dapat menjawab hipotesa dari penelitian yang dilakukan.

2. Hipotesis

Hipotesis yang telah ditetapkan dari penelitian ini adalah terdapat hubungan antara variabel penggunaan media internet dengan variabel minat belajar Mahasiswa Angkatan 2018 Program Studi Bimbingan dan Konseling FKIP Universitas Sriwijaya. Hipotesa ini dapat diterima apabila didapatkan $r$ hitung lebih besar dari $\mathrm{r}$ tabel $=\mathrm{rh}>\mathrm{rt}$. Pada penelitian ini, analisis data Adapun hasil dari uji korelasional pada penelitian ini adalah menggunakan rumus korelasi product moment pearson dengan hasil sebagai berikut :

$$
r_{x y}=\quad \frac{\mathrm{N} \sum \mathrm{xy}-\left(\sum \mathrm{x}\right)\left(\sum \mathrm{y}\right)}{\sqrt{\left[\mathrm{N} \sum \mathrm{x} 2-\left(\sum \mathrm{x}\right) 2\right]\left[\mathrm{N} \sum \mathrm{y} 2-\left(\sum \mathrm{y}\right)^{2}\right]}}
$$

Berdasarkan hasil dari perhitungan yang telah dilakukan dengan menggunakan rumus korelasi Product moment didapatkan hasil dari nilai koefisien adalah korelasi sebesar 0,574 pada taraf signifikan 0,05 maka dapat disimpulkan bahwasannya hasil dari $r$ hitung adalah lebih besar dari pada $r$ tabel yaitu 0,574 lebih besar dari 0,23. Maka dapat disimpulkan bahwasannya terdapat hubungan yang signifikan antara penggunaan internet sebagai media pembelaran dengan minat belajar. Hasil dari korelasi kedua variabel berada pada tingkat sedang yang dapat dilihat tingkatnya pada tabel kategorisasi korelasi. Hubungan antar kedua variabel ini menunjukkan adanya hubungan yang positif. Hasil yang menunjukkan positif artinya hipotesis dapat menunjukkan bahwasannya penelitian dapat diterima, yaitu terdapat terdapat hubungan antara penggunaan media internet dengan minat belajar Mahasiswa Program Studi Bimbingan Angkatan 2018. Di mana adanya tingkat yang semakin tinggi dalam penggunaan internet sebagai media dalam pembelajaran maka akan mempengaruhi juga tingkat yang kearah lebih tinggi juga pada minat belajar yang ada pada diri mahasiswa.

\section{Simpulan}

Internet merupakan sebuah perantara yang diperlukan oleh khalayak banyak dalam menunjang berkomunikasi dan berbagi informasi secara online sehingga dapat berjalan dengan cepat dan efektif khususnya dalam bidang Pendidikan, kesehatan, teknologi, pekerjaan dan komunikasi. Hasil dari penelitian diatas menunjukkan hasil bahwasannya tingkat penggunaan internet sebagai media pembelajaran pada mahasiswa 
rata-rata berada pada kategori sedang yaitu berjumlah 52 orang mahasiswa. Internet dapat menjadi sebuah teknologi yang efektif dalam membantu dan menunjang mahasiswa dalam menjadi individu atau pribadi yang kreatif dan inovatif apabila dimaksimalkan seefektif mungkin. Apabila kelengkapan fasilitas atau layanan yang disediakan internet dapat dimanfaatkan dengan baik dan efektif maka kedepannya para mahasiswa juga diharapkan agar dapat lebih baik dan dapat lebih bijak dalam memanfaatkan dan menggunakan internet secara maksimal untuk mencari informasi-informasi yang bermanfaat bagi dirinya khususnya pada bidang akademis.

Media dalam pembelajaran merupakan sebuah perantara yang menyalurkan sejumlah informasi dari berbagai sumber informasi yang tersedia kepada para informan (Falahudin, 2014). Adanya media pembelajaran dapat membantu untuk merangsang bagaimana individu dapat memproses pemahaman serta minat nya dalam belajar. Tafonao (2018), dalam penelitiannya menjelaskan bahwasannya media pembelajaran khususnya internet dapat membantu individu dalam mengembangkan kemampuan dalam menguasai teknologi serta memudahkan dalam memahami materi yang belum didapatkan disekolah.

Simatupang (2017), dalam penelitiannya juga memaparkan bahwasannya terdapat hubungan yang signifikan antara penggunaan media berbasis internet dengan minat belajar siswa, dan dapat disimpulkan dari hasil penelitiannya bahwa semakin tinggi penggunaan internet maka semakin tinggi pula minat belajar siswa. Muhibbin Syah (2005), pada penelitiannya menyampaikan bahwasannya secara umum, faktor yang mempengaruhi minat belajar dipengaruhi oleh dua faktor yaitu faktor internal dan juga faktor eksternal, kebutuhan internal yang mendorong adanya minat belajar adalah adanya kebutuhan dalam mengakses informasi dan memperoleh ilmu pengetahuan yang baik dan bermanfaat bagi diri sedangkan faktor eksternal yang menunjangnya adalah penggunaa internet sebagai media dalam pembelajaran. Penggunaan media internet sebagai salah satu sumber dari perolehan informasi dalam proses belajar dapat menjadi proses belajar menjadi lebih efisien dan efektif. Melalui media internet, individu dapat memperoleh informasi yang lebih luas, informatif dan bermanfaat. Selain itu juga mahasiswa juga dapat mengakses internet tanpa adanya batasan tertentu.

Dengan demikian, dapat disimpulkan bahwasannya melalui penelitian ini dapat diperoleh kesimpulan mengenai bagaimana hubungan dari penggunaan internet sebagai media pembelajaran dengan minat belajar mahasiswa. Hasil yang didapatkan menunjukkan bahwasannya nilai koefisien korelasi dari kedua variabel adalah sebesar 0,574 yang mana berad pada kategori sedang. Hal tersebut menunjukkan bahwasannya terdapat hubungan yang signifikan antara kedua variabel tersebut. Selain itu, berdasarkan hasil dari perhitungan yang telah dilakukan oleh peneliti juga menunjukkan bahwa sebesar 39,2\% variabel penggunaan internet sebagai media pembelajaran memiliki kontribusi terhadap pengaruh pada variabel minat belajar sedangkan sisanya yaitu sebesar $67,1 \%$ dipengaruhi oleh faktor lainnya yang dapat mempengaruhi variabel tersebut seperti bagaimana kondisi diri individu pada saat belajar, serta bakat yang dimilikinya.

\section{Referensi}

A. S, Rosa, M. Shalahuddin. 2015. Rekayasa Perangkat Lunak. Bandung: Informatika Bandung. Abdulloh, Rohi. 2015. Web Programming is Easy. Jakarta: PT Elex Media Komputindo. Ardana, MM., Ak. CA, Drs. I Cenik, and hendro Lukman, SE., MM., CPMA.,CA., CPA. 2016. Sistem Iinformasi Akuntasi. Jakarta: Mitra Wacana Media.

Arisanti, Devi, and Mhd. Subhan. 2018. "Pengaruh Penggunaan Media Internet

Terhadap Minat Belajar Siswa SMP Kota Pekanbaru." Jurnal Al-Thariqah 3(2): 61-66. doi:10.25299.

Aulia, Normi , Ellyn Normelani, and Nevy Farista Aristin. 2016. "Pengaruh Pemanfaatan Internet Terhadap Hasil Belajar Geografi Siswa Kelas XII IPS MAN 2 Kandangan." JPG (Jurnal Pendidikan Geografi) 3: 32. doi:10.20527.

Cahyono, Gunawan Rudy, Saberan, and Marlina Hidayati. 2018. "Sistem Informasi Rekam Medik Klinik Hewan Dan Sistem Pakar Diagnosa Penyakit Sapi Menggunakan Metode Certainty Factor." Jurnal Poros Teknik 10: 38-48.

E. Y. A., and Rita Irvani. 2017. Pengantar Sistem Informasi. Andi.

Ferdika, Mikhael, and Heri Kuswara. 2017. "Sistem Informasi Penjualan Berbasis Web Pada PT Era Makmur Cahaya Damai Bekasi." Inrofmation System for Educators and Profesionals 1: 175-188.

Fikri, Sirhan, Wahyu Wiyani, and Agung Suwandaru . 2016. "Pengaruh Kualitas Layanan Terhadap Kepuasan dan Loyalitas Mahasiswa." Jurnal Bisnis dan Manajemen 3: 120-121.

Hamid, Mustofa Abi, and dkk. 2020. Media Pembelajaran. Medan: Yayasan Kita Menulis.

Hardiyan, Hardiyan, and Ayu Chentia Kusuma Devi. 2014. "Rancangan Sistem Informasi Rawat Jalan Berbasis Web Pada Klinik Hewan Puri Kembangan Kedoya." SNIPTEK 410. 
Hariyanto, Eko, and Pinton Setya Mustafa. 2020. Pengajaran Remedial dalam Pendidikan Jasmani. Banjarmasin: Lambung Mangkurat University Press. Hayat. 2019. Managemen Pelayanan Publik. Depok: PT RajaGrafindo Persada.

Hudaya, Juang, and Affan Nur Alamsyah. 2016. "Perancangan Sistem Informasi Management Data Pasien Dokter Hewan Panggilan." Indonesia Medicus Veterinus 474-484.

Kusumastuti, Suci Wulandari, Faiza Renaldi, and Dian Nursantika. 2017. "Sistem Informasi Pusat Kesehatan Hewan Kota Cimahi." Prosiding SNATIF 399.

Lengkana, Anggi Setia , Cecep Supriadi, Dadang Budi Hermawan, and Aji Mirwan Soleh. 2017. Prosiding Seminar Nasional Pendidikan Jasmani 2017

Implementasi Model Pembelajaran Penjas dan Modifikasi Alat Belajar. Sumedang: UPI Sumedang Press.

Manopo, Cendy Chaterine, Sri Wahyu Widyaningsih, and Sri Rosepda Br.

Sebayang. 2020. "Analisis Minat Belajar Mahasiswa FKIP Universitas Papua pada Pembelajaran Online." Silampari Jurnal Pendidikan Ilmu Fisika 2: 122. doi:10.31540.

Ni'mah, Ulyn, Ali Bowo Tjahjono, and Ghofar Shidiq. 2019. "Pemanfaatan Internet sebagai Sumber Belajar Pendidikan Agama Islam." Conference on Islamic Studies (CoIS) 329. doi:10.30659.

Nurrita, Teni. 2018. "Pengembangan Media Pembelajaran untuk Meningkatkan Hasil Belajar Siswa." Misykat 3: 177. doi:10.33511.

P., ANDI ACHRU. 2019. "Pengembangan Minat Belajar dalam Pembelajaran."Idaarah 3: 211. doi: 10.24252 .

Purba, Ramen A, and dkk. 2020. Pengantar Media Pembelajaran. Medan: Yayasan Kita Menulis.

Ricardo, and Rini Intansari Meilani. 2017. "Impak Minat dan Motivasi Belajar Terhadap Hasil Belajar SI." Jurnal Pendidikan Manajemen Perkantoran 190-191. doi:10.17509.

Rosidi, Yogi Husien, Farida Arinie S, and Hudiono. 2017. "Rancang Bangun Aplikasi Sistem Informasi Pada Klinik Kesehatan Kucing Berbasis Android." Jurnal JARTEL 4: 185-186.

Suardi, Moh. Yogyakarta. Belajar dan Pembelajaran. 2018: Deepublish.

Susanto, Ahmad. 2013. Teori Belajar dan Pembelajaran di Sekolah Dasar. Jakarta: Prenamedia Group.

Sutrisno. 2021. Meningkatkan Minat dan Hasil Belajar TIK Materi Topologi

Jaringan dengan Media Pembelajaran. Malang: Ahlimedia Press.

Syahputra, Edy. 2020. Snowball Throwing Tingkatkan Minat dan Hasil Belajar. Sukabumi: Haura Publishing.

Syardiansah. 2016. "Hubungan Motivasi Belajar dan Minat Belajar terhadap Prestasi Belajar Mahasiswa Mata Kuliah Pengantar Manajemen (Studi kasus Mahasiswa Tingkat I EKM A Semester II)." Jurnal Manajemen dan Keuangan 5.

Wardana, I Cenik, and Hendro Lukman. 2016. Sistem Informasi Akuntansi. Jakarta: Mitra Wacana Medi 